\title{
Aesthetic Reflection on P.E. Teaching Courseware Design
}

\author{
Qing Lan \\ Yichun University, Yichun, Jiangxi, China
}

\begin{abstract}
P.E. is a discipline to interpret the beauty of the body and its actions. P.E. teaching involves a process of transferring beauty. P.E. teaching courseware should follow several aesthetic principles, so as to serve the purposes of informing and inspiring as well as those of entertaining and refining the mind. This paper discusses the principles for utilizing the composition, color, text, pictures and in aesthetic designing, those for promoting the artistic result of the courseware, aiming at a product with both practicability and artistic value, which can serve to improve the result of P.E. teaching.
\end{abstract}

Keywords: P.E. teaching, teaching courseware

\section{INTRODUCTION}

With the development of computer technology, teaching courseware is applied to all respects of P.E. teaching extensively. In P.E. theory course, multimedia teaching coursewares, with its vividness, rich image, large informative, convenient use, strong interactivity, are favored by teachers. In P.E. skill course, coursewares are took as an effective tool for classroom demonstration of action, with the help of courseware to teach action specification and detail, be of great help for students to master the action skills. As the matter of fact, teaching courseware bearing teacher's teaching emotion, teaching skills and artistic accomplishment, which content are caught by students' sense organ together with course of the teaching. As an edge tool of P.E., teaching courseware should not merely be practical, should be the carrier of professional knowledge and be instruments for transmitting beauty according to students' aesthetic standards and reading habit. A well designed courseware be imperceptible yet more effective on helping students to obtaining scientific knowledge and have a taste of beauty.

\section{II.THE AESTHETIC VALUE OF P.E. TEACHING COURSEWARE}

P.E. is a bilateral activity of the teaching and learning of knowledge and experience in the classroom, sports venues and other places, it is scientific, and also has artistry. P.E. has abundant and deep aesthetic intension, it is a multifunctional education entity, and it is a life activity course of containing aesthetic education in body exercise for promoting the human body. P.E. teaching contains the beauties such as human body, health, spirit, action and fashion. The teacher should pursue the expression of beauty, should represent the aesthetic intension of sports in terms of beauty in teaching. In the classroom, teachers should pay attention to the aesthetic feelings such as dress, movement, emotion, language and calligraphy. Suhomlingsky, educationist of the former Soviet Union, has pointed out: "There are three steps in education and teaching course: Science, skill and art. If you want to obtain the excellent teaching result and achieve the goal of educating people's teaching in an allround way, it must pay attention to the artistry of teaching in foundation of pursuing the scientific of teaching."

Modern teaching equipment make teaching structure and teaching form changed, the use of the multimedia teaching courseware has changed the traditional dull and oppressive teaching mode, it has melt in sound, video, shape, color as an organic whole, and it has produced the good stimulation to students' visual and auditory organs, therefore, teachers should pay attention to the practicability of the courseware, should fully excavate the aesthetic value of the courseware, let the student obtain aesthetic education and edification in the experience of pleasing audio-visual.

\section{III.AESTHETIC ELEMENTS OF P.E. COURSEWARE}

\section{A- Principles of aesthetic design in P.E. teaching courseware}

Student can feel beauty while watching the teaching courseware, one of the most direct reasons is that beauty is of visibility. Chernyshevsky has said: "Aesthetic feeling, sense of hearing and vision were combined together." Aestheticism is originally about a delight caused by such stimuli as colors, lines, sounds and so on, in that the material structure of them corresponds with the biological and psychological structures of students, thus raising resonation between them. Human's vision and sense of hearing are the most important study sensory organs, they are also the most important aesthetic sensory organs, therefore, the excellent courseware uses the benign stimulus of them to improve students' study interest and stimulate students' study enthusiasm. Visual elements rendering is more important than auditory elements rendering in the P.E. teaching courseware, this is because sports beauty is mainly transmitted by means of the former.

\section{1)The main points of composition in the courseware page}

The multimedia courseware serves for teaching. its final purpose is to transmit knowledge effectively. So, the first important task that the courseware is designed should have clear information to transmit the main body. We should plan proper arrangement to information according with students' visual habit and learning regulation while designing the courseware page, to highlight its main body, which is convenient for students to read. Generally 
speaking, the simple, succinct page with outstanding subject is easier to be accepted by students.

According to Arnheim's visual theory "it is balanced to be different from the weight on physics, people can produce a kind of psychological equilibrium on certain condition too while accepting the physique of a certain thing visually." Therefore, teaching courseware should pay attention to the visual balance of courseware pages. What is called vision balanced, but until visual symbol transmit at the state that it is relatively balanced to in one kind in the works various elements in the design, it give somebody a kind of equilibrium sense visually.

In order to produce the change visually and reflect the creator's individual character, teachers attempt to create the uneven element in the equilibrium sometimes. This kind is uneven might not realize through very deceitful page overall arrangement, so long as make some changes on the lightness, colour, space in a flexible way, can produce the uneven feeling. Using the uneven element in balanced patterning make the courseware seem calm and steady and rich in the sensation of movement.

In the P.E. teaching courseware, the teacher often shows action with video, or set off the page atmosphere by contrast with Gif cartoon picture. However, if there are too many movement elements, it will lead to the fact that the page will glimmer everywhere, students are at a loss as to what to do. So, it is unsuitable to introduce too many sport elements in the single page, the page is ornamental for not influencing the subject element. In the course of designing, the teacher should consider the whole style of the page, which let all pages inherit the unified style in a courseware promptly; And also consider the change of the page, for courseware more sensations of movement and metres in verse through many kinds of methods such as overall arrangement, colour, switching over the result.

\section{2) Choice of color}

When students catch colour through the vision, they can induce out the emotional responses corresponding to it. For example, when it is arranged according to the beautiful form that a certain colour forms, it is joyful that students not merely can get sense organ among them, still can get the distillation of spirit, otherwise, will lose concern and interest about it, even produce the mood detested, conflicted.

Different colours can initiate different psychology to react, the colours such as being red, orange, and yellow can bring the excited and warm feeling; the colours such as being and blue, green can produce the calm and peaceful feeling. Concrete colour is chosen and should be designed in a flexible way according to the properties of course, in the P.E. courseware, the warm tones is used for displaying the sport passion extensively, but it will cause students' psychology to be tired to pass the long stimulus too much, so, regard quiet colour as the fundamental key, the colour taking active colour as light spot matches the mode and can yet be regarded as a kind of safe colour design plan. Colour is the way in which the visual information transmits. it is a language of art design. Based on scientific knowledge of colour, and then canvass the form of expression that colour is designed in terms of aesthetics, can strengthen the artistry of the P.E. courseware works greatly.

3) Design of the page characters

Character is a basic carrier of information dissemination, it is a most direct, most common and most apt way to transmit information, and it is also one of the most basic key elements that the courseware is designed. In making of the P.E. courseware, the artistic expression of the characters has important meanings. In the composing design of the characters, should consider the visual procedure of the page characters and distinguish the relation between principal and subordinate of the content of the characters. Human physiological structure of eyeball determine vision of people can only produce a focus twinkling of an eye, so, arrange the visual procedure rationally and put the visual focus in main content and important title of the characters, contribute to the whole coordination and aesthetic of the page. The choice of the font is very important too, Windows operating system offered the commonly Chinese and English fonts to user, can meet the general need of making of courseware, but if the user has special demands on font, he can also use such fonts as Han-Yi, Han-Ding, Wen-Ding by third party developed. Generally speaking, font that uses in the same page should not need more, it is need giving overall consideration and matching meticulously. In addition, while the teacher is demonstrating the courseware with other computers, it is also need to consider the font library of different computers is possible not totally the same, therefore, teachers should not use the font library that developed by third party too much in the courseware, so as not to present font unusually while having a class.

4. Edition of pictures

Pictures are an important component of the courseware, in that compared with characters they are ocular, vivid, convenient for students to understand and accept, and can express information which would be difficult to express in characters. For example, in order to represent the posture in twinkling of an eye of a movement, the teacher often inserts photos in the courseware, but replace photos with the picture sometimes. The photo can reflect the reset condition of action faithfully, and the picture drawn meticulously can collect main information out from the photo, give up interference information, make the courseware page cleaner and clearer, let the courseware have artistic results even more, it can reflect the teacher's understanding course and thinking inclination and facilitate students understanding and knowing the main point of knowledge.

When there are both characters and pictures on the page, proper decisions concerning when to use characters and when to use pictures should be made according to the 
content of course. when pictures be taked as the core, it should be placed on the visual centre and be complemented with the explanatory note; when characters be taken as the core, the picture should play a role in setting off and be weakened treatment. In addition, proper arrangement in rhythm and grasp the occurrence in order between characters and pictures can give courseware more sense of rhythm and cadence in the teaching procedure.

\section{B- P.E. courseware should fully show human body beauty and sport beauty}

One is the intelligent part of the universe. The human body is most beautiful things. Great painter, scientists and physician Da Vinci in Italy thinks, the person is the most sacred and human body is the most beautiful object in nature. Human body beauty has lofty status in the aesthetic ideological system," Discobolus", "Venus" is the model of men and women's callisthenic physique more than 2,000 years ago, still have enormous glamour so far. People have formed the beautiful common standard to human body gradually from the aesthetic practice, namely, bodily form is well-balanced, the skin is bright and clean, muscles are strong and the posture is coordinated. Human body beauty of sports is the most able to reflect a person's physical and mental outlook and most has the breath of life and social value. Foundation of sports give body beauty to "health" and "force", which makes the beauty of human body from the internal mechanism to external form all seem to be full of vitality.

In the basic theory lessons of sports such as sports anatomy and physiology, the teacher often shows some human organ drawing to student, some aestheticists think the drawing of human organ though have ocular images, but can't cause the aesthetic experience, it is not beautiful. In fact, this kind of view is biased. The reason why excellent human organ drawing can represent scientific content of the human body accurately is that it benefits from the painting skill and technique of fine arts to a great extent. It combines human body's scientific content and plastic arts together, the skill and technique of using fine arts to paint while displaying scientific content of the human body, form scientific art of the human body beauty. It pays attention to the form of composition expression, flexible application of point, line, surface, and quite particular about the choice of color. The excellent human organ drawing works should possess the characteristic with clear content, harmonious color, clear level, while students are appreciating such works, they not merely can realize pattern beauty, color beauty, the lines beauty, but also can realize rigorous work and hard-working of medical science workers and sports science workers and realize the scientific beauty of human body pictures.

Display the beauty of human body, sports beauty in the courseware, It is not the simple accumulation of motion pictures, can let the student feel the beauty of human body, sports beauty while watching the teaching courseware, depends on whether teachers can according to the teaching content and aesthetic principles on teaching material compilation and re-creation. Motion picture photography and choose if we can learn the aesthetics principle photography and painting, the light, color, background processing are carefully designed, is able to enhance the artistic effect of the courseware.

To show human body beauty and sports beauty in the courseware is not merely sports pictures pile up, students could experience the human body beauty and sports beauty in the course of watching the teaching courseware that absolutely depend on teachers can sort out and recreate teaching source material according to content of courses and aesthetic principle. Shooting and choosing of sports pictures draw lessons from the theory of art of photographing and painting, designing meticulously to deal with the light, color, and background etc. in that can promote the artistic result of the courseware.

\section{C- Artistic distillation of the P.E. teaching courseware}

P.E. teaching is a teaching activity with the purpose of human body, sport and healthy true features appearing, but this kind appears do not the same to look in the mirror, it is a kind of kinetic and creative reflection, but not machinery, mechanical, passive and negative reflection. In the aesthetic practice of P.E. teaching, the objective aesthetic target has stimulated the teacher's heart activity of carrying on Lenovo, abundant, supplementary and recreating to the aesthetic target, thus it can strengthen aesthetic feeling to experience and strengthen the aesthetic emotion.

Teacher's pursuit to P.E. courseware can surmount the general content of courses and seek the creation of the thinking, idea and emotion, in that the courseware can surmount the category of the general teaching aid and possess the value of art appreciation. This demands teacher to carry on beauty creation using understanding of interesting, requirement, ideal and beauty rules that be formed in longterm teaching practice. Sports beauty is scattered, and everybody is not the same in understanding of it, but the teacher can centralize, refine and alteration it according to one's own aesthetic Sentiment and aesthetic ideal , in that sports beauty be made further more distinct conspicuous in the courseware and become art beauty different from that in the sport activity. Teachers follow the theory of art to carry on the activity that art is processed to the courseware works, in that the courseware have characteristic of work of art. General coursewares all have effect on educating students and improving their knowing, but the artistic courseware works are more vivid and appeal, its reason that the latter conceals tendentiousness in the image and reside hiding educationally in amusement. To opposite abstract theory, image and amusement are easy to be accepted generally by students. Students have deepened the understanding unconsciously while appreciating the image. Courseware works could give 
full play to education function is only through students enjoy it. Therefore, the creation of P.E. teaching courseware works is not merely piling up sports theories, but it take the fancy of student with the abundant artistic image. It is unified spiritual activities of intuitions and understands as well as emotion and knowing when Students are appreciating such courseware works.

\section{IV.AESTHSTIC MISTAKEN IDEAS OF P.E. TEACHING COURSEWARE}

\section{A. With " many " For "beauty"}

Some teachers ask demanding perfection of more characters on courseware, they put all the contents on the page that they know and think of , lacking of arrangement and refinement of the page characters, teaching courseware has become the traditional meaning of "move of books". Such a courseware is not only read tiredly by the teacher also will let students see it dazedly, hear dog-tiredly and drowsy finally, too much information not merely makes students unable to concentrate the visual focus on the key information that a teacher attempts to express while reading on the page, will even influence studying enthusiasm because of being at a loss as to what to do. Meanwhile, too many animation effect, color configuration and font change will lengthen students to stimulating the time and cause the vision and psychology of students to be tired.

The rational contrast relation between characters and the blank one can strengthen aesthetic feeling of page. This kind of blank can be kept around picture or characters and should avoid staying in the middle, in that students' attention intensity can not reduce. The subtle of blank uses is that students can obtain the breather, put the state of mind in order and raise the concern while they are meeting the appropriate blank or stop in courseware. The blank is that one kind accumulates implicit beauty including delight. Courseware can detach free from philistinism, obtain fresh graceful unique artistic conception and sublimate teacher's idea by using blank brilliantly, thus the artistic grade of courseware be improved.

\section{B. Courseware pursue the vision strike one-sidedly and neglect the rational beauty}

Some coursewares attempt to give somebody a kind of strong vision strike by pursuing magical color, novel pictures, audio-video frequency and complicated cartoon. Such a courseware is really "Something Completely New", it is seem to liven up outstandingly too while having a class. Students can remember the magical change of the courseware after class, but lack enough memory to the knowledge among them. It is not so abundant to solve the aesthetic problem of P.E. teaching courseware just through the result of seeing and hearing, because it has only solved the form of beauty, but can't explain how to hold rational content beauty. Because beauty has the happiness of the purpose besides the form of the law and must has the contents of idea, consciousness and rational, or not has the feeling of material and biological. The good result of seeing and hearing can cause the happy feeling, but this kind of happiness is only a kind of more low-grade physiological pleasant sensation, though it can promote people's aesthetic feeling, it is not the basic reason that the aesthetic feeling produces after all. Coursewares neglect content beauty and emotion beauty for pursuing result of Audiovisual and paying attention to form beauty of courseware unilaterally. Excessive strike of vision will interfere with the student concern in professional knowledge. Excellent courseware ought to with beauty as the fundamental key. CHEN Wang-dao has made some insightful comments on graceful: "it does have no press, it does have no violent, it does have no conflict, it does have no dispute, it does just extremely natural, it does just extremely soft, it does just a feeling as if the bright moon is soaked in". The beautiful works can influence students' aesthetic temperament and interest silently.

In teaching, the courseware is only the carriers rather than knowledge after all, it is just "adjuvant material" or not "main material", thus teachers should put more attention on the content of the courseware. The courseware content should meet demands of student that only associates with students' need can cause their mood and emotion. Aesthetic feeling is a kind of advanced spiritual activity that it can not caused by the satisfaction of the general physical need. The formulation of aesthetic feelings come from student's understanding that the courseware content can meet one's own spirit's needs activity, and this kind of understanding activity is foundation and reason that the aesthetic feeling depends on happening. Meanwhile, the excellent P.E. teaching courseware should include the respect to the life, to healthy love and the pursuit to faster, higher, stronger sportsmanship.

\section{V.CONCLUSION}

The frequency of utilization of the teaching courseware is not the same in different courses of sports discipline, in the teaching of some basic courses, courseware is the most important teaching handling tool, but in Sport-Profession courses, courseware is just use to demonstrate some action details that are difficult to use of languages in the presence of condition. Making courseware is a time-consuming thing, it is need unremitting devotion and inspiration got by chance with a highly skill. Teachers only have pursuing perfect faith firmly and improving one's own artistic accomplishment constantly, they can create out the rich in artistry and educational courseware works constantly.

\section{REFERENCES}

[1] Cao, Y.H. 1997. Aesthetics and aesthetic education. Beijing: China.

[2] Liao, H.Y. 2001. On the Aesthetic Significance and Psychological Effects of Physical Education. Journal of Hubei Sports Scicnce. 20(3): 51-52. 
[3] Zhao, H.G. 2006. Teacher introduction to aesthetic education. Nanchang: China.

[4] Li, Z. 2006. A discussion on multimedia teaching art of college major courses. Agriculture Network Information. (11): 79-81.

[5] Zhao, Z.Q. 2008. Discussion on aesthetics of seeing and hearing improving teaching effects of multimedia. Journal of Changchun University. 18(2): 102-104.

[6] Ning, H.L. 2010. Arne's dynamics theory of visual perception form and China ancient aesthetics. Art. (7): 125-127. 